\title{
The Role of Mutations on HLA Genes in Lambert-Eaton Myasthenic Syndrome
}

\author{
Mahsa Hemati ${ }^{1}$, Naser Shagerdi Esmaeli ${ }^{2}$, Shahin Asadi ${ }^{3 *}$ \\ 1Department of Pharmacology and Toxicology, School of Pharmacy, Islamic Azad University, Tehran, Iran. \\ 2Department of Laboratory Hematology and Blood Bank, Shahid Beheshti University of Medical Science, Tehran, Iran. \\ 3Medical Genetics-Harvard University. Director of the Division of Medical Genetics and Molecular Optogenetic Research \& Massachusetts Institute \\ of Technology (MIT)
}

*Corresponding Author: Shahin Asadi, Medical Genetics-Harvard University. Director of the Division of Medical Genetics and Molecular Optogenetic Research \& Massachusetts Institute of Technology (MIT)

\section{Received date: October 11, 2021; Accepted date: October 28, 2021; Published date: November 02, 2021}

Citation: Mahsa Hemati, Naser Shagerdi Esmaeli, Shahin Asadi. (2021) Effect of Ultrasound Guided Bilateral Greater Occipital Nerve Block on Serum Calcitonin Gene Related Peptide (CGRP) in Chronic Migraine. J. Neuroscience and Neurological Surgery. 10(1); DOI:10.31579/2578-8868/213

Copyright: () 2021 Shahin Asadi, This is an open-access article distributed under the terms of The Creative Commons Attribution License, which permits unrestricted use, distribution, and reproduction in any medium, provided the original author and source are credited

\begin{abstract}
Lambert-Eaton myasthenic syndrome (LEMS) is a rare presynaptic disorder of neuromuscular transmission in which quantal release of acetylcholine (ACh) is impaired, causing a unique set of clinical characteristics, which include proximal muscle weakness, depressed tendon reflexes, posttetanic potentiation, and autonomic changes. ${ }^{[1]}$ The initial presentation can be similar to that of myasthenia gravis $(\underline{\mathrm{MG}})$, but the progressions of the 2 diseases have some important differences.

LEMS disrupts the normally reliable neurotransmission at the neuromuscular junction (NMJ). This disruption is thought to result from an autoantibody-mediated removal of a subset of the P/Q-type Ca2+ channels involved with neurotransmitter release.
\end{abstract}

Keywords: lambert-eaton myasthenic syndrome (lems); genetic mutation; hla gene; autoimmune disorder

\section{Overview of Lambert-Eaton Myasthenic Syndrome (LEMS)}

LEMS syndrome is an autoimmune disorder of the neuromuscular junction. This is a false connection between the nerve cell and the muscle that leads to the gradual onset of muscle weakness. Symptoms of this syndrome begin in the proximal muscles of the legs or arms. LEMS can be classified into two distinct categories: small cell lung cancer-associated LEMS (SCLC) and cancer-free LEMS. Approximately 60\% of patients with LEMS have SCLC, and the onset of LEMS symptoms often precedes the diagnosis of cancer. Patients with LEMS with cancer tend to get older - mostly men - and almost always have a long history of smoking. In patients with no accompanying cancer, the onset of the disease can be at any age and be gender neutral. LEMS may affect the quality of life of patients, depending on the severity of the symptoms [1].

\section{Clinical Signs and Symptoms of Lambert-Eaton Myasthenic Syndrome (LEMS)}

LEMS is characterized by weakness and fatigue, especially in the muscles of the legs and arms. It can affect a patient's ability to do strenuous exercise and can make activities such as climbing stairs or walking on a steep path difficult. It starts gradually and usually lasts for a few weeks to a few months. There are often symptoms that progressively affect the shoulder muscles, leg and arm muscles, speech and swallowing muscles, and eye muscles. Symptoms progress more rapidly when LEMS is associated with cancer. Most LEMS patients also show the following symptoms (sometimes called autonomic symptoms): dry mouth, dry eyes, constipation, impotence, and decreased sweating. LEMS patients with or without cancer may also experience significant weight loss. Tendon reflexes are reduced or absent on medical examination. Hence, in summary, LEMS is often described as a clinical "triple" of proximal muscle weakness, autoimmune symptoms, and decreased tendon reflexes [1]. 




$\checkmark$ receptors $4 \mathrm{ACh}$

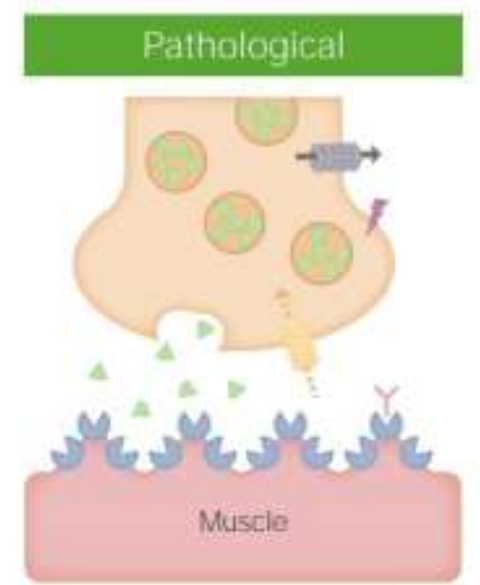

$\mathrm{Ca}+$
$\mathrm{ACh}$

vesicles

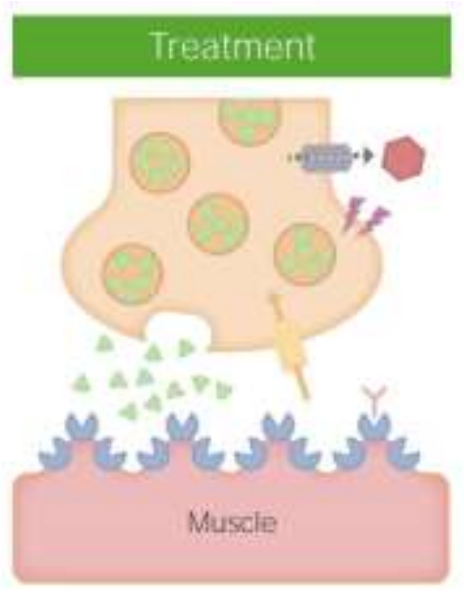

3.4 DAP

Blocks K+ channel

increasing opening time for VGCC

Figure 1: Schematic of a normal muscle cell versus a muscle cell with LEMS [1]

\section{Etiology of Lambert-Eaton Myasthenic Syndrome (LEMS)}

LEMS is an autoimmune disorder. Autoimmune disorders occur when the body's natural defenses against "foreign" or invasive organisms (for example, antibodies) begin to attack healthy tissue for unknown reasons. LEMS occurs because the antibodies damage the voltage-gated calcium channels (VGCCs) in the motor nerve membrane at the junction of the muscle nerve. These channels normally carry calcium to the nerves, releasing a chemical called acetylcholine. Acetylcholine helps connect nerve cells and muscles and is a group of chemicals known as neurotransmitters that help transmit nerve impulses. Antibodies attack the VGCC, resulting in decreased acetylcholine secretion [1,2] .

In patients with LEMS associated with cancer, an immune-mediated response is initiated because VGCC is present on the surface of cancer cells and the immune system stimulates the production of antibodies to fight cancer cells. Antibodies made against VGCC on small cell lung cancer are believed to mistakenly attack VGCC in nerve membranes instead. Smoking is one of the most important risk factors for SCLC, and in patients with LEMS associated with cancer, a long history of smoking is also an important factor [1,2] .

\section{Lambert-Eaton Myasthenic Syndrome: Ig $G$ antibodies cause $P / Q$ type VGCC loss}

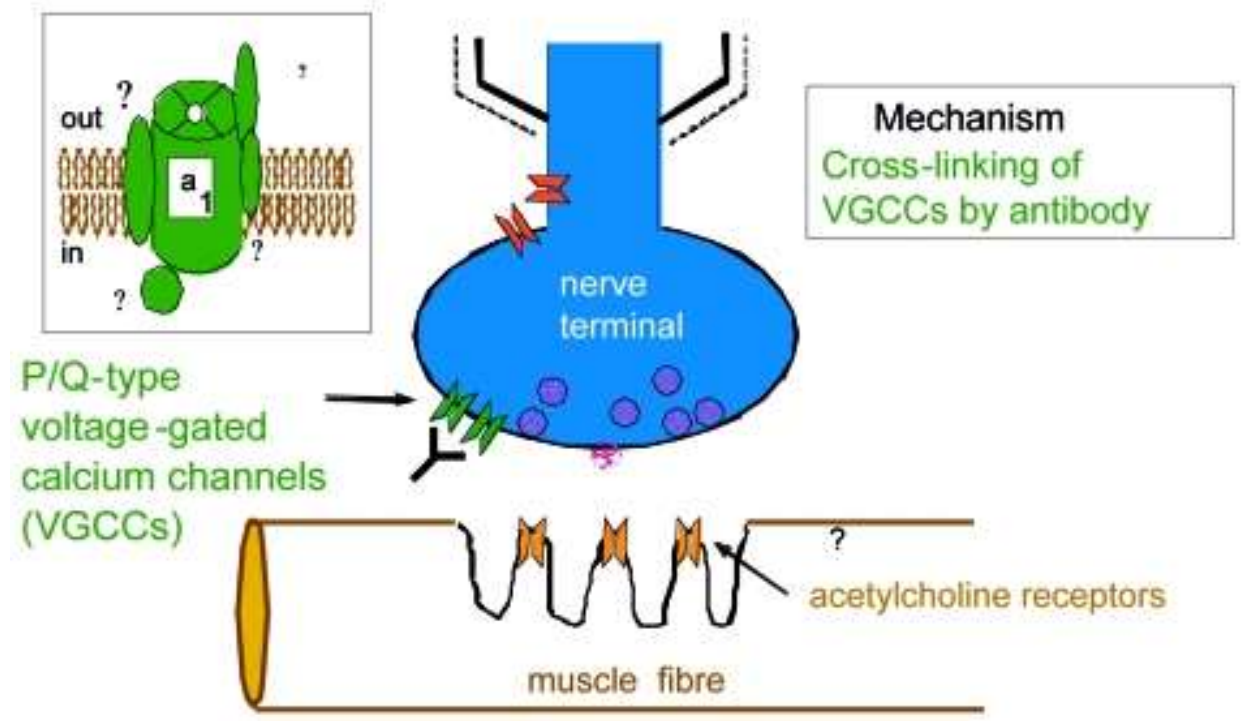

Figure 2: Schematic of the biochemical mechanisms of nerve cells and muscle cells in LEMS [1].

In people without LEMS without cancer, there is a genetic link to human leukocyte antigen (HLA) genotypes. HLAs are proteins that are also present on the cell surface and their function is to regulate the human immune system. However, it is still unknown what causes these proteins to break down and produce antibodie $[1,3]$. 


\section{Prevalence of Lambert-Eaton Myasthenic Syndrome (LEMS)}

The estimated prevalence of LEMS worldwide is about 2.8 per 1 million people, making it a rare disease. There are approximately 400 known cases of LEMS in the United States. When LEMS is associated with SCLC, patients tend to get older and men are more likely to be affected by the syndrome than women. The average age of onset of SCLC is about 60 years. Approximately 3\% of SCLC patients also develop LEMS, but the clinical signs of LEMS usually precede the diagnosis of SCLC (sometimes by years). When LEMS is not associated with cancer, the syndrome can occur at any age and typically begins around age 35. LEMS is very rare in the pediatric population and so far only 11 children have been reported in the medical literature. $[1,3]$.

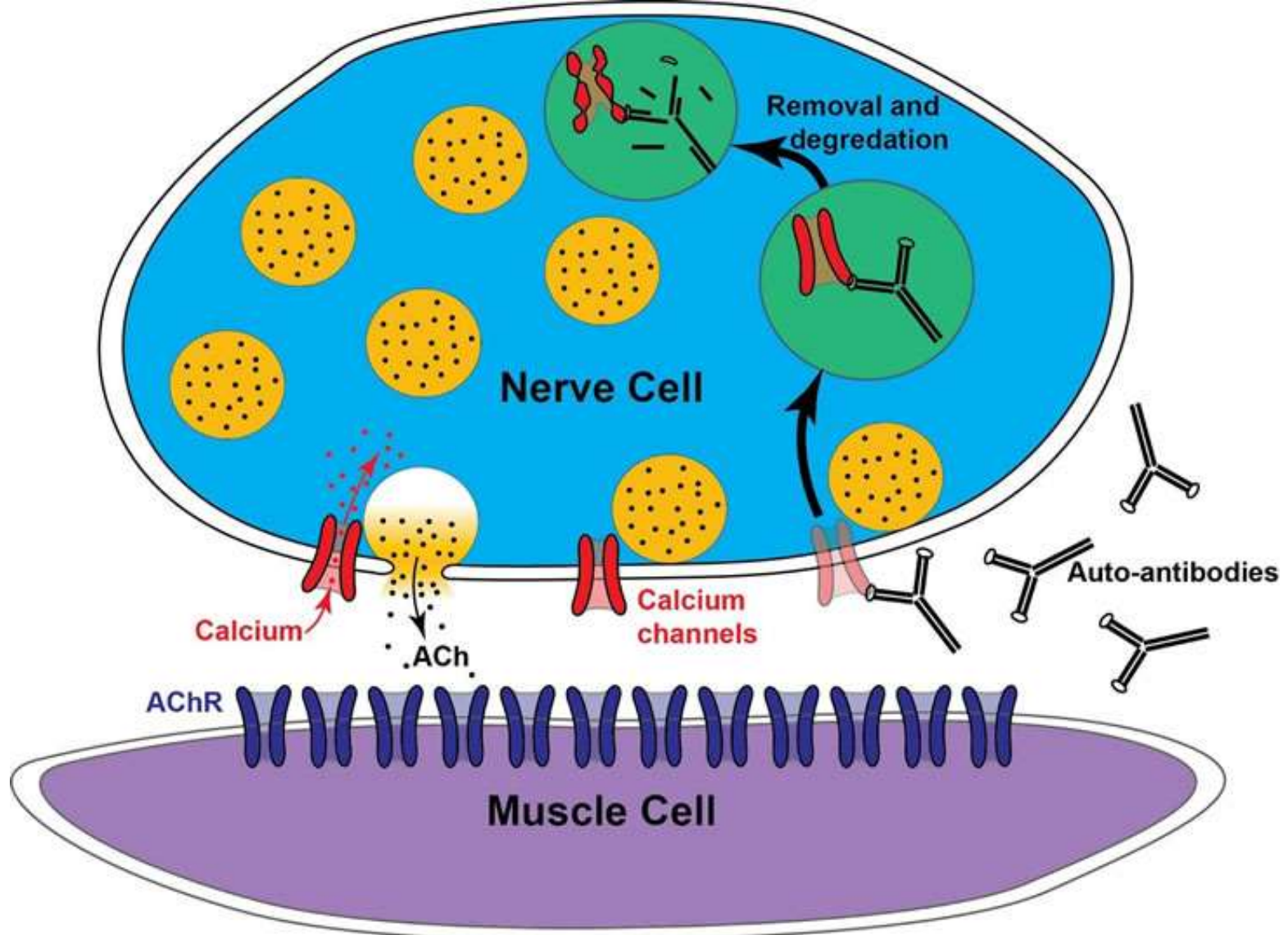

Figure 3: Schematic of the biochemical mechanism of antibodies in nerve cells and muscle cells with LEMS [1]

In people without LEMS without cancer, there is a genetic link to human leukocyte antigen (HLA) genotypes. HLAs are proteins that are also present on the cell surface and their function is to regulate the human
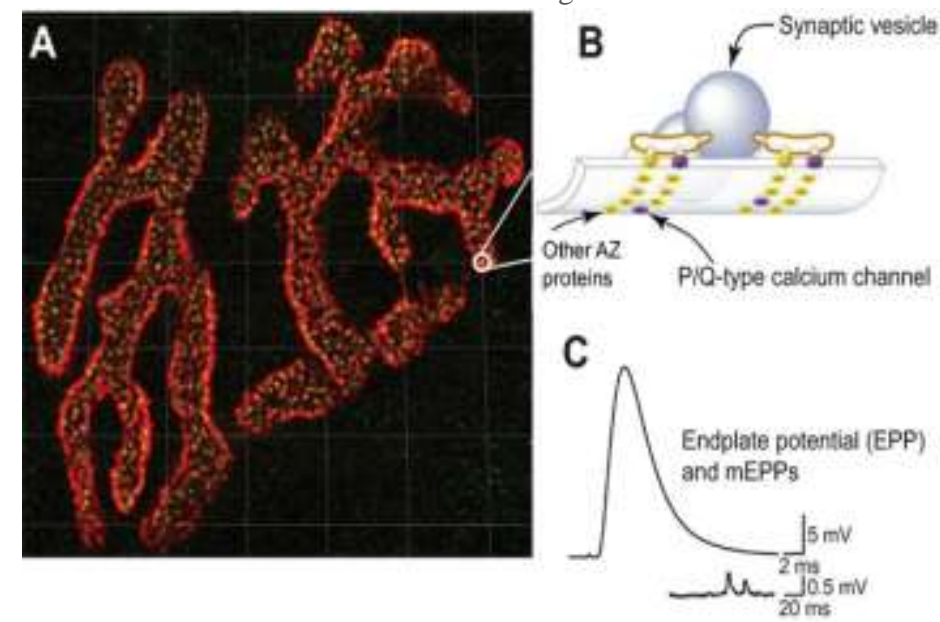

immune system. However, it is still unknown what causes these proteins to break down and produce antibodies. [1,4] .

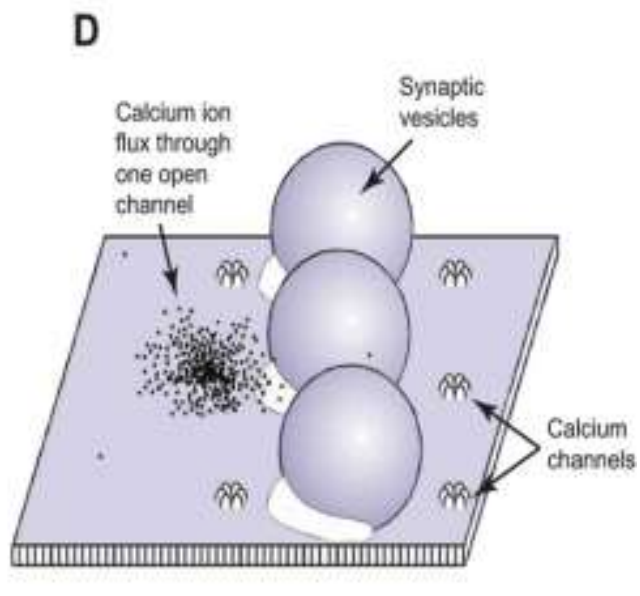




\section{Disorders associated with Myasthenic Syndrome (LEMS)}

The symptoms of the following disorders may be similar to those of Lambert-Eaton syndrome. A comparison may be useful for the differential diagnosis of this syndrome:

Myasthenic gravis (MG) is a chronic neuromuscular disease characterized by abnormally rapid weakness and fatigue of the sphincter muscles and

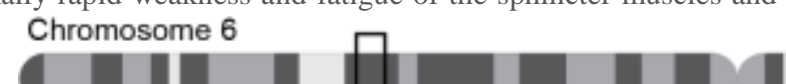

resolves upon rest. Each muscle group may be affected, but the area around the eyes and the muscles used for swallowing are more involved. Often, because of the similarity in symptoms, LEMS is misdiagnosed as MG, but there are fundamental differences. In LEMS, eye muscle weakness, if present, is mild and, unlike MG, is almost never the only symptom. Severe respiratory muscle weakness, which can be fatal in MG, is rare in LEMS. There are no autonomic symptoms in MG that affect most LEMS patients. [1,5] .



Figure 5: Schematic of chromosome 6 where HLA genes are located in the short arm of this chromosome [1]

Guillain-Barré syndrome is an autoimmune disease that causes damage to the myelin and axons of the nerve when the body's immune system attacks the nerves. Nerve signals are delayed and altered, causing weakness and paralysis of the muscles of the legs, arms, and other parts of the body. Abnormal feelings such as numbness or tingling may also occur. If the nerves are damaged, the patient experiences muscle pain and weakness, shortness of breath, and difficulty swallowing. If the autonomic nervous system is damaged, the patient may experience changes in blood pressure, heart rate, vision, body temperature, bladder function, and blood chemotherapy. [1,6] .

\section{Diagnosis of Lambert-Eaton Myasthenic Syndrome (LEMS)}

The diagnosis of LEMS is based on clinical signs and symptoms. Several diagnostic test methods are available to help diagnose LEMS. Electrophysiological studies are performed to measure muscle response and muscle strength. Repetitive nerve stimulation measures the electrical 
activity of a muscle during stimulation. Antibody testing is performed to detect the presence of anti-VGCC antibodies. [1,7].

Electromyographic results usually show a decrease in the combined motor performance potential (CMAP). Repetitive nerve stimulation initially shows a small amount of electrical activity in the muscle. After repetitive stimulation or high-repetition exercise, muscle activity increases. [1,8].

Anti-VGCC antibodies are detectable in approximately $85 \%$ of LEMS patients and are very specific to the disease if diagnosed. This is because anti-VGCC antibodies are found in LEMS with SCLC and in LEMS without cancer association. [1,9] .

Screening for SCLC is a very important part of the diagnostic process of LEMS. Chest CT (and sometimes FDG-PET) is usually the basis of this screening. Depending on the hazard profile, a negative initial screen is repeated at appropriate intervals. A recently discovered tumor marker antibody against the SOX gene, found in 65\% of SCLC LEMS patients and absent in only $5 \%$ of non-tumor LEMS patients, may contribute to clinical treatment in the future. $[1,10]$.

\section{Treatment Pathways in Lambert-Eaton Myasthenic Syndrome}

Treatment for LEMS may vary depending on the presence of the accompanying cancer. If cancer is present, treatment first includes canceroriented therapies, which alone may help relieve the symptoms of LEMS. $[1,11]$.

There is no cure for LEMS, and treatment usually involves improving patients' quality of life. The FDA recently approved a new drug to relieve the symptoms associated with muscle weakness called Firdapse (amifampridine). It is a potassium channel blocker that works by increasing the secretion of acetylcholine. It is currently the only approved drug to improve the quality of life of LEMS patients. This drug has been shown to have significant benefits such as improving muscle strength and CMAP. In addition, it is a tolerable drug. $[1,12]$.

If Firdapse alone does not improve symptoms, there are other options that can be added if symptoms improve. Mestinon has been shown to treat MG, but is often used in combination with Firdapse to treat the symptoms of autonomic dysfunction (dry mouth, dry eyes, constipation, impotence, and decreased sweating). In MG, Menstinon improves muscle strength, but in LEMS, it only improves the symptoms of autonomic dysfunction. $[1,13]$.

In 2019, amifampridine was approved for the treatment of LEMS in patients 6 to 17 years of age. This is the first FDA treatment specifically approved for children with LEMS. [1,13] .

Immunosuppressive drugs (immunosuppressive drugs) are used in LEMS patients with more severe symptoms, such as prednisone (alone or in combination with azathioprine or cyclosporine). In some patients, a highdose course of immunoglobulin may prevent further progression of the disease. Genetic counseling is also essential for all parents who want a healthy baby. $[1,13]$.

\section{Discussion and Conclusion}

LEMS syndrome is an autoimmune disorder of the neuromuscular junction. This is a false connection between the nerve cell and the muscle that leads to the gradual onset of muscle weakness. Symptoms of this syndrome begin in the proximal muscles of the legs or arms. LEMS is characterized by weakness and fatigue, especially in the muscles of the legs and arms. It can affect a patient's ability to do strenuous exercise and can make activities such as climbing stairs or walking on a steep path difficult. It starts gradually and usually lasts for a few weeks to a few months. There are often symptoms that progressively affect the shoulder muscles, leg and arm muscles, speech and swallowing muscles, and eye muscles. In patients with LEMS associated with cancer, an immunemediated response is initiated because VGCC is present on the surface of cancer cells and the immune system stimulates the production of antibodies to fight cancer cells. Screening for SCLC is a very important part of the diagnostic process of LEMS. Chest CT (and sometimes FDGPET) is usually the basis of this screening. Depending on the hazard profile, a negative initial screen is repeated at appropriate intervals. There is no cure for LEMS, and treatment usually involves improving patients' quality of life. The FDA recently approved a new drug to relieve the symptoms associated with muscle weakness called Firdapse (amifampridine). It is a potassium channel blocker that works by increasing the secretion of acetylcholine. $[1,13]$.

\section{References}

1. Asadi S, Pathology in Medical Genetics Book, Vol 20, Amidi Publications, Iran, 2021.

2. Schoser B, Eymard B, DattJ, Mantegazza R. Lambert-Eaton myasthenic syndrome (LEMS): a rare autoimmune presynaptic disorder often associated with cancer. J neurol. 2017;264(9):1854-1863.

3. Abenroth DC, Smith AG, Greenlee JE, Austin SD, Clardy SL. Lambert-Eaton myasthenic Syndrome: epidemiology and therapeutic response in the national veterens affairs population. Muscle and Nerve. 2017;56(3):421-426.

4. Ha JC, Richmound DP. Myasthenia gravis and related disorders: pathology and molecular pathogenesis. Biochim Biophys Acta. 2015; 1852(4):651-657.

5. Mantegazza R, Meisel A, Sieb JP, et al. The European LEMS registry: baseline demographics and treatment approaches. Neuro Ther. 2015;2015(4):105-124.

6. Morgan-Followell B, de los Reyes E. Child neurology: diagnosis of Lambert-Eaton myasthenic syndrome in children. Neurology. 2013;80:220-222.

7. Gilhus NE. Lambert-Eaton myasthenic syndrome; pathogenesis, diagnosis and therapy. Autoimmune Dis. 2011;201:973-808.

8. Keogh M, Sedehizadeh S, Maddison P. Treatment for LambertEaton myasthenic syndrome. Cochrane Database Syst Rev. 2011;(2):CD003279.

9. Quartel A, Turbeville S, Lounsbury D. Current therapy for Lambert-Eaton myasthenic syndrome: development of 3,4diaminopyridine phosphate salt as first-line symptomatic treatment. Current Medical Research and Opinion. 2010;26(6):1363-1375.

10. Titulaer MJ, Lang B, Verschuuren JJ. Lambert-Eaton myasthenic syndrome: from clinical characteristics to therapeutic strategies. Lancet Neurol. 2011;10(12):1098-1107.

11. Titulaer MJ, Klooster R, Potman M et al. SOX antibodies in small-cell lung cancer and Lambert-Eaton myasthenic syndrome: frequency and relation with survival. J Clin Oncol. 2009;27(26):4260-4267.

12. Online Mendelian Inheritance in Man (OMIM). The Johns Hopkins University. Calcium Channel, Voltage-Dependent, BETA-2 Subunit; CACNB2. Entry No: 600003. Last Edited $11 / 06 / 2014$

13. Stickler DE. Lambert-Eaton Myasthenic Syndrome (LEMS). Medscape. Updated: Dec 26, 2018. Accessed January 29, 2019. 
(C) (7) This work is licensed under Creative Commons Attribution 4.0 License

To Submit Your Article Click Here: Submit Manuscript

DOI: $10.31579 / 2578-8868 / 213$
Ready to submit your research? Choose Auctores and benefit from:

$>$ fast, convenient online submission

$>$ rigorous peer review by experienced research in your field

$>$ rapid publication on acceptance

$>$ authors retain copyrights

$>$ unique DOI for all articles

$>$ immediate, unrestricted online access

At Auctores, research is always in progress.

Learn more auctoresonline.org/journals/neuroscience-and-neurologicalsurgery 